\title{
Use of Technology in Open and Distance Education: A Guideline for the Educational Institutions in Bangladesh
}

\author{
Saria Islam \\ Lecturer, Computer Science and Engineering \\ Bangladesh Open University \\ Gazipur - 1705
}

\author{
A.S.M. Mahmudul Hasan \\ Lecturer, Computer Science and Engineering \\ Bangladesh Open University \\ Gazipur - 1705
}

\begin{abstract}
Bangladesh is a densely populated developing country. Development of a country highly depends on education. It is quite impossible for a developing country to educate all their citizens as resources and other facilities are limited. Huge amount of money is required to establish such infrastructure and facility. Open and distance learning (ODL) is an affordable solution to this problem. It is an important part of the education system now. It covers a large number of people for imparting education. This education system is very helpful for those who are unable to attend at the traditional class room program. Technology is now entered into all parts of the society. The ODL education system is also benefited with the wide application of different technological tools. The goal of this paper is to show the advancement of technology in ODL system, so that it can help many educational institutions to offer programs in distance learning mode. It is the only way to bring the quality education to everyone's door step in Bangladesh.
\end{abstract}

\section{General Terms}

Open and distance education, distance learning, internet, technology, video conferencing.

\section{Keywords}

Distance education, Open University, Bangladesh Open University, open and distance education in Bangladesh, Technology in distance education.

\section{INTRODUCTION}

We are living in an age of knowledge and technology. The government of Bangladesh has declared the country as 'Digital Bangladesh'. The effect of technological development has changed a developing country like Bangladesh also. The Distance Education Technologies are also expanding at an extremely rapid rate [1].

Open and Distance Education or Open and Distance Learning (ODL) is a quite old approach to education [2]. Distance education has a history that spans almost two centuries and this time period represents significant changes in how learning occurs and is communicated [3]. The open and distance learning education is now an important part of the education system as it covers a large number of people for imparting education. This education is beneficial for those who are unable to attend at the regular class room program [4].

Modern technologies such as computer, communication and media are being utilized in conventional and non-conventional mode of education. The information technologies enabled open and distance learning education system is now become so sophisticated that one can get his or her desired education just with a click away. The rapid use of internet and other communication facilities have brought the open and distance education closer to the student community [5]

This paper discusses how technology can influence the development and implementation of ODL in Bangladesh. It also describes specific technology and their applications in ODL, so that it can help the educational institutions to understand how they can develop ODL in Bangladesh.

\section{IMPORTANCE OF ODL IN BANGLADESH}

In Bangladesh, the cycle of compulsory basic education is from age 6 to 10. Only about half of children in Bangladesh reach the end of primary school. The main reasons behind dropout are given bellow [6]

* Children drop out because they cannot get to school easily enough. In Bangladesh, up to four-fifths of the population is still rural, typically making their livelihood through subsistence farming. In the more remote rural settings, children drop out of school or never attend school because getting to school is such a problem. Government of Bangladesh primary schools are built according to population criteria, and so in the more remote locations with much lower density of population, the distance to school is much greater.

* The difficulties of accessing education when living in a remote location are exacerbated for children belonging to an ethnic minority. For example, in the tea plantations in Srimangal in Bangladesh, where workers were brought over from India generations ago, the children speak Sylheti, and languages such as Oriya, and many are Hindu. They live with their parents on land belonging to the tea companies, and although their employers are responsible for providing schools, the single school may be located on the other side of the plantation and offer only a Bangla-medium education.

* In the cities in Bangladesh, access to government schools can also be a geographical issue. Governments cannot build schools in slum areas on private land where people are squatting and they may in any case be reluctant to endorse the establishment of unplanned communities.

* The need for urban children to contribute to the family can also be paramount. Altogether it is estimated that in Bangladesh about $40 \%$ of urban slum children aged 6-10 are out of school. Urban working children may attend irregularly or drop out of school because there is not enough purpose in education and there are more pressing needs. 
* For children who are caught up in disaster or conflict, the process to complete withdrawal can sometimes be more immediate than the gradual withdrawal from school which is typical of other kinds of dropout.

Open and distance learning is rapidly becoming an alternative to traditional classrooms in Bangladesh [7]. Students can benefit from the flexibility that comes with distance learning, and for students who don't have the time or money to attend traditional schools, distance learning can provide a path to higher education. The following shows how open and distance learning can help dropout students in Bangladesh.

* Distance learning can increase access to education for students who aren't located near a school or who can't afford to travel to class daily. Even commuting from work to school on a daily basis can cost a significant amount of money and eat up time that the student could be earning money at work. Distance learning can increase opportunities for students of Bangladesh, ensuring that students don't have to choose a school based solely on its location.

* Open and distance learning is less expensive, because students aren't helping to pay for a brick and mortar building or an expensive university campus [8]. Because teachers have more flexibility with scheduling, they may be able to conduct more classes, which mean more revenue for the school without an increased charge to the student.

* Distance-based learning offers more flexibility to students in terms of how and when they take classes. Many distance-based courses allow students to use several different learning modules, such as online message boards, chat rooms, video conferences and recordings of lectures, making distance learning a highly customizable educational option. Students can choose when they do their work, and at some schools, may even be able to attend classes, via videotaped lectures, at various times rather than following a set schedule.

* Not all students thrive in a traditional lecture setting, and some students may even be made anxious by large groups. Distance learning enables students from many walks of life to attend school. A critically ill student, for example, might attend his classes from his hospital bed, while a student with severe anxiety might be less intimidated by distance courses. For students with physical disabilities, distance learning means they can avoid navigating a challenging college campus.

\section{CATEGORIES OF TECHNOLOGIES USED IN ODL}

The used technology that is found today in the DTIs in order to support the educational process varies, and it is difficult to be categorized. However, most DTIs [9] use the following ways to strength the offering of education to their students:

Face-to-face meetings / tutorial Session: Technology can help, at least, with the multimedia software and the presentation software. The data projector suppresses the overhead projector and does the presentation more attractive with sound and picture.

Student Services: The World Wide Web constitutes space of report of various information. Its use study programs, the reminder of obligations of the students and certain important dates constitute usual phenomenon for most open and distance education.

Study Material: The World Wide Web, apart from space of information, can be useful also as space of assistance of the study programs. This tactic is usual also in the traditional educational institutions. Thus, students via the World Wide Web, from the library or their personal computer can have access to the educational - teaching material that refers to all the study program or part of these.

Usually the teaching material of the study programs via World Wide Web includes:

a) The teacher's introduction with multimedia elements, which can be with text or with compressed video.

b) Special software relative to the material, which is received via the network or the student can "download" it and work with his personal computer.

c) Other educational materials, which the student can "download" in his personal computer, such as: files of text with questions, files of sound and pictures, files of video.

d) Exercises / activities for practice, written tests (even for being-line completion and automatic correction).

e) Connections with information resources, such as: libraries, published articles in the World Wide Web and scientific journals.

\section{TECHNOLOGIES USED IN OPEN AND DISTANCE LEARNING}

Technologies used to support ODL can be classified into two main categories, the first being hardware and second being, software. The hardware currently in use are radio, television, telephone (land, mobile, fax, Voice over Internet Protocol or VoIP), and computers. Fiber optic cables, satellite and microwave transmission facilities made enhancements to the technological infrastructure.

Much variation can be observed in the software components needed to support distance education (DE). Such DE software tends to be customized to address variables such as: specific applications or purpose for which it will be used; the combination of hardware used to support DE applications; and features that need to be incorporated to meet users' needs. Customized forms of software is typically evident in the form of learning management systems (LMS) that are used to simulate classroom settings and facilitate academic discussions or interactions. LMS are often meshed with other, pre-existing technologies such as databases and digital libraries.

Thus, various forms of LMS and their related hard- and software-components necessitates the formulation of appropriate polices, processes, and procedures that must align with preexisting policies, processes, and procedures - all of which must work in concert to support the smooth operation of the technology.

\subsection{Delivering instructional content}

\subsubsection{Instructional Television (ITV)}

Since most people have watched television, the medium is familiar. Motion and visuals can be combined in a single format so that complex or abstract concepts can be illustrated through visual simulation. Instructional television is an 
effective way to take students to new environments (the moon, a foreign country, or through the lens of a microscope). Time and space can be collapsed, so that events can be captured and relayed as they happen. It is very effective for introducing, summarizing, and reviewing concepts. It can be used effectively as a motivational tool.

\subsubsection{Computers}

Computer applications for distance education fall into four broad categories:

a) Computer Assisted Instruction (CAI)- uses the computer as a self-contained teaching machine to present discrete lessons to achieve specific but limited educational objectives. There are several CAI modes, including: drill and practice, tutorial, simulations and games, and problem-solving.

b) Computer Managed Instruction (CMI)- uses the computer's branching, storage, and retrieval capabilities to organize instruction and track student records and progress. The instruction need not be delivered via computer, although often CAI (the instructional component) is combined with CMI.

c) Computer Mediated Communication (CMC)- describes computer applications that facilitate communication. Examples include electronic mail, computer conferencing, and electronic bulletin boards.

d) Computer-Based Multimedia- HyperCard, hypermedia, and a still-developing generation of powerful, sophisticated, and flexible computing tools have gained the attention of distance educators in recent years. The goal of computer-based multimedia is to integrate various voice, video, and computer technologies into a single, easily accessible delivery system.

\subsubsection{Print}

Print materials can be used in any setting without the need for sophisticated presentation equipment. The medium of delivery should enhance, not compete with, the content for the learner's attention. If the student reads well, the print medium is the most transparent instructional medium of all. Reading is second nature to most students. As a result, they are easily able to focus on the content, without becoming mesmerized or frustrated by the process of reading itself. Given adequate light, print materials can be used any time and any place without the aid of supplemental resources such as electricity, viewing screen, and specially designed electronic classrooms. The portability of print is especially important for rural learners with limited access to advanced technology. Print materials are typically learner-controlled. As a result, the student rapidly moves through redundant sections, while focusing on areas demanding additional attention. No instructional tool is less expensive to produce than print. In addition, facilities abound for the inexpensive duplication of these materials. In comparison to technically sophisticated electronic software, print is both easy and inexpensive to edit and revise. When instructional print materials are created, the developer's primary focus remains on content concerns, not the technical requirements of the delivery system.

4.1.4 Video

Types of Videoconferencing Systems are- a) Small room videoconferencing- This system is designed primarily for small groups (1-12 participants) at all sites seated around a conference table.

b) Classroom videoconferencing- This type of system usually uses high quality AV components, codecs, and an interface that allows all participants to be seen on the monitors.

c) Desktop videoconferencing- This system utilizes a personal computer and videoconferencing software. These systems are less expensive, but offer limited resolution. They are most effective for individual and small group use.

\subsection{Delivering Support Services to Learners}

The success of learners depends on the various support services available to them. Moreover, the delivery of student support services must be congruent with the mode of delivering instructional content. Support services like tutorials, library, guidance and counseling, and academic and administrative consultations, must be available in a wide variety of forms, such as online and via SMS. This is very important because many Bangladeshi do not have easy and ready access to the Internet. As mentioned, cellular phone technology is proving to be an indispensable tool. For instance, SMS can be used for vital communications, such as alerting students that their course materials are ready and that they must make the effort to download these materials from the university website.

\subsection{Research and Development Work}

Research and development is integral to the informed use of ICT for education. However, aside from being the subject of research itself, ICTs can also be used to gather much needed data on geographically distributed subjects such as students, university staff in the learning centers, etc. Put simply, surveys are now being conducted online, via email, via online interviews using VOIP or Skype or other forms of audio and videoconferencing. Collecting and analyzing data is also being automated using appropriate software for data analysis. Survey questionnaires can be downloaded and submitted online and tabulation of data gathered can be automatically integrated and analyzed with statistical software.

\subsection{Performing Management and Administration Functions}

ICT has influenced the delivery of instructional content and student support services and has transformed the management of distance education institutions [10]. Although most are online, many ODL universities choose to maintain their physical presence locally and internationally. Such 'physical presence' is typically manifest in their learning and testing centers. Use of ICT has clearly become central in facilitating and coordinating communication and activities between and among ODL institutions' widely dispersed service and academic units. Indeed, specific applications to facilitate administrative processes underway in ODL institutions include:

\subsubsection{Application for admission}

Through this system, students can submit their applications online, receive acknowledgement of receipt, track the progress of their application, and receive results of their evaluation online. Moreover, because much of these 
administrative processes are now fully automated, students have access to more efficient, cost-effective services.

\subsubsection{Online registration system}

The online registration system allows the student to enroll in courses at their own convenience, typically during the prescribed registration period. A parallel, traditional registration system is also available for those who do not have access to the Internet or do not own a cell phone.

\subsubsection{Online submission of grades}

The online grades submission system enables instructors to submit students' grades online. This system is especially useful for faculty members who work externally. Online access to official student enrolment lists is also available, where instructors can post students' interim and final grades for immediate release to students.

\subsubsection{Digitization of student records}

Many universities are now using digital student records. Indeed, a typical student accumulates a variety of records over his or her academic lifetime. Clearly, the storage of physical records not only takes up a lot of space, it can take a lot of time and effort, not to mention lead to nightmares as one seeks to retrieving archived student files.

\subsubsection{Orientation of new/ incoming Students}

Orientation activities are required to inform students about course prerequisites, course outlines, procedures for adding and withdrawing from classes, grading criteria, tips on where to access study materials, and so forth. The fact that many students live far away from main and satellite campuses, however, makes it very impractical - if not impossible - to gather them physically all in one location for orientation. The creative use of low-cost, readily available technologies like Yahoo Messenger or video conferencing technology like Skype for instance, has helped distance education providers overcome obstacles of time and space and levels of synchronous communication and interaction necessary to conduct viable orientation sessions.

\subsection{Enculturation and Promotion}

Disseminating fully informed, research-based evidence about the benefits of distance education can help correct misperception. Put simply, broader and more targeted dissemination of DE research results can help to,

* Rally policy makers and resource providers to support distance education

* Enhances distance education's credibility in the eyes of industry and other groups whose personnel may benefit from distance education, or conversely, may hire graduates of distance education programs

* Secure funding for academic institutions seeking to use DE modalities to reach student populations previously unattainable

Given that most academic institutions have finite financial resources, however, money needed to promote, support, and sustain distance education enculturation is simply not there or must be shared. Put simply, distance education often must take the backseat and remains last on a long list of pressing priorities. As a result, many institutions must share their limited resources to promote their distance education offerings. Currently, most distance education promotional activities take place online via universities' main websites, homepages dedicated to its DE faculty, publishing and making distance education research papers available, publishing e-New stories on distance education, SMS broadcasts, etc. As a result, ICTs have been helpful in getting the message out there, helpful in distance education 'image building.' In short, use of ICT ensures the greater likelihood of distance education reaching its target market, specifically those seeking flexible certificate, degree, and non-degree programs delivered at a distance.

\section{ENSURING QUALITY EDUCATION IN A TECHNOLOGY-DRIVEN MODE OF LEARNING}

Quality of DE has always been contentious. Detractors of distance education, somehow equate quality of DE with that of physical face-to-face traditional education in the classrooms. This viewpoint, however, is like comparing apples to oranges - both are fruit, but both are very different. Nonetheless, perceptions need to be based on reality. This means it is necessary to employ the 'quality circle' approach in developing DE courses and learning materials. The 'quality circle' consists of the course writer (who is a subject matter expert), a subject matter specialist (another subject matter expert who peer reviews the soundness of the course and its contents), an instructional designer (who ensures the 'chunking of lessons' is appropriate and that the program/ course goals, contents, and assessments mesh logically with one another), a media specialist (who recommends appropriate delivery mediums), a language editor (who performs copy and substantive editing). In sum, whatever the technology used to deliver instructional content, the 'quality circle approach' to course development should be standard practice.

Educational providers must strive to use quality and reliable ICT hardware (connections should be available, 24/7) and software (i.e., the LMS). Just as important, these systems must be supported by highly skilled individuals, armed with the knowledge and skills they need to ensure hard and software runs smoothly. To accomplish the human aspect of ICT, institutions must offer training to various user groups (i.e., students, teachers, administrators, etc.). Offering such training helps to ensure the efficient and effective use of ICT for all stages of the teaching and learning process, from accessing online classrooms, to course registration, to managing digital library materials, to manipulating databases to get the information one needs to do their work or complete an assignment and so forth.

\section{CONCLUSION}

The growing use of Internet technologies for distance education opens new educational possibilities that move well beyond the provision of more sophisticated delivery tools. The communication and instruction possibilities made feasible by the interconnected network foster exchanges among students and instructors, and among students in the classroom. The open navigation opportunities increase learner control of the instructional experiences. These elements render the Internet a unique tool for distance education, one that allows a real shift from an instructor-centered learning paradigm to a real student-centered learning domain. With students' access to a variety of resources, the need arises to render a more flexible course design process taking into account learner exigencies, and shaping the instructional elements. This paper represents the use of technology in ODL to help the 
educational institutions to offer distance education. $\mathrm{Ti}$ is shown here, how to control the quality of education in ODL. In future the cost analysis of establishing ODL will be outlined in the context of Bangladesh.

\section{REFERENCES}

[1] Srinivas, S R. 'The Use Of Media And Technology In Distance Education - Indian Context'. African Research Review 1.2 (2008): n. pag. Web. 22 Nov. 2015.

[2] Mikropoulos, T. A. (2000). On the pedagogy of open and distance learning systems. Departmentof Primary Education, University of Illinois, Hellas amikrop@cc.uoi.gr

[3] Spector, J. Michael. Handbook Of Research On Educational Communications And Technology. New York, N.Y.: Springer, 2014.

[4] Information and communication technology and its impact on open and distance learning. In: 'Globalization and Indian Economy'. Edited by Runu Bhattacharyya. 2012. pp.72-

82.

[5] Akande, Samson Oyeniyi, "Computer and Internet Facilities Use in Distance Education: A Survey of Sandwich Students of Universityof Ado-Ekiti, Nigeria"
(2011). Library Philosophy and Practice (e-journal). Paper 452.

[6] "Open and Distance Learning for Basic Education in South Asia", Cambridge Distance Education Consultancy, Von Hügel Institute, St Edmund's College, Cambridge, UK and UNICEF Regional Office for South Asia

[7] Islam, Md Tofazzal, and Abu Sadeque Md. Selim. 'Information And Communication Technologies For The Promotion Of Open And Distance Learning In Bangladesh'. Journal of Agriculture \& Rural Development 4.1 (2008): n. pag. Web.

[8] Thompson, Van. 'Importance Of Distance Learning'. Everyday Life - Global Post. N.p., 2015. Web. 8 Nov. 2015.

[9] Gerson, Steven M. 'E-CLASS: Creating A Guide To Online Course Development For Distance Learning Faculty'. Online Journal of Distance Learning Administration 3.4 (2000): n. pag. Web. 5 Nov. 2015.

[10] Brindley, Jane E, Olaf Zawacki-Richter, and Christine Walti. Learner Support In Open, Distance And Online Learning Environments. Oldenburg: Bis, Bibliotheksund Information system der Universität Oldenburg, 2004. Print. 